\title{
Emergence of Homogeneous Social Class? Commonalities and Differences of the New Middle Class in Globalizing East Asia ${ }^{1}$
}

\author{
Shigeto Sonoda ${ }^{*}$
}

Rapid economic growth and social change have produced large new middle class populations in big metropolises in East Asia. Some scholars claim that these emerging new middle class populations will be a foundation for a future building of East Asian Community because of their similar life-styles and value orientations. Due to a lack of comparative research on middle class populations, however, these claims are made without empirical underpinnings.

In this paper, the author explores some hypotheses on the characteristics of new middle class populations, such as the younger generation hypothesis or the feminization hypothesis, by using the data of AsiaBarometer 2006, which covers seven East Asian societies, namely, Japan, South Korea, China, Hong Kong, Taiwan, Vietnam, and Singapore. Results of data analysis revealed the fact that new middle class populations are much better educated, more exposed to globalization, and more fluent speakers of English than working class populations in every part of East Asia. As to socio-political orientations, however, these new middle class populations don't show any clear or distinctive characteristics in every society. They are apt to be more supportive of gender-equality policy and environmental protection and pro-democratic than working class populations, but there is no clear distinction between these populations in some societies like Singapore. Interestingly, cluster analysis tells us that there are two types of new middle class populations in East Asia: one can be called 'English-speaking type' and the other can be called 'Confucian type.' The latter type is huge in volume, and it is highly educated but less exposed to globalization probably due to its lacking in English fluency. The "Confucian type" middle class is more secularized and particularistic than the 'English-speaking type' in nature.

Finally, the author explores the complex relationship between globalization and the formation of new middle class in East Asia.

\section{Background}

Rapid economic growth and social change have produced large new middle class populations in big metropolises in East Asia. From kohdo keizai seicho (rapid economic growth) in the 1960s onwards, Japan produced a large middle class population. The growth of new this middle class has prompted many sociologists to pay attention to these emerging new classes in urban Japan.

\footnotetext{
1 This is a revised version of the author's early paper. Sonoda, Shigeto, 2006, "New Middle Class in Confucian Asia: Its Socio-cultural Background and Socio-political Orientations in Comparative Perspective," Working Paper Series for Contemporary Asian Studies, Waseda University.

* Shigeto Sonoda is Professor of Sociology at Institute of Oriental Culture and Graduate School of Interdisciplinary Information Studies, the University of Tokyo. His main research fields are comparative sociology, contemporary China studies and globalization of cultures in Asia. He has published extensive books including Social Inequality in China (Chuo-Koron, 2008 in Japanese) by which he was awarded Special Prize of $20^{\text {th }}$ Asia-Pacific Award in 2008.
} 
Though the concept of 'middle classes', or 'class' itself, is not in fashion in contemporary Japan due to her affluence and standardized way of life, ${ }^{2}$ other East Asian metropolises are using the concept of 'urban middle class' in describing their changing societies.

In the case of South Korea, for example, the political roles and ideological traits of middle classes have received attention since the late $80 \mathrm{~s}$ when they began to achieve democratization and political reform. ${ }^{3}$ Taiwanese sociologists have also worked hard toward understanding the socio-political traits of emerging middle classes from the $1980 \mathrm{~s}^{4}$ in Taiwan, as well as their Hong Kongese and Singaporean counterparts. ${ }^{5}$

It is probably in urban China now that the analysis of middle classes is most popular among sociologists in East Asian countries. Drastic marketization and rapid economic development under the socialist regime is now producing a unique middle class in China, sometimes called bailing (white-collar), and many sociologists have been trying to determine their number or characterize their socio-political orientations through empirical studies. ${ }^{6}$ The author also conducted middle class surveys in four cities, namely Tianjin, Shanghai, Chongqin, and Guanzhou, to identify their changing characteristics during this decade. ${ }^{7}$ Because of the "localization" of middle class research in each society, comparative analyses of middle class have been very rare in East Asia except in several cases. Hsiao's extensive research of middle classes in East Asian cities, namely in Seoul, Taipei, Hong Kong and Singapore is a pioneering project which produced many breakthroughs in the research in these regions, ${ }^{8}$ but Hsiao's two projects on Northeast Asia and Southeast Asia were conducted independently and no paper was published dealing with middle classes in both Northeast and Southeast Asian countries. Hattori's project tried to cover middle class issues in South Korea, Hong Kong, Singapore, Malaysia, the Philippines and Thailand, ${ }^{9}$ and Sonoda's research covered South Korea, China and Hong Kong, ${ }^{10}$ but no com-

\footnotetext{
${ }^{2}$ Hara, Junsuke. and Kazuo Seiyama, 1999, Shakai Kaiso (Social Stratification), Tokyo: University of Tokyo Press, p.214, and Hara, Junsuke, 2000, "Kindai Sangyo Shakai Nihon no Kaisho Sisutemu (Social Stratification System in Japan as a Modern Industrialized Society)" Hara, J. ed., Kindaika to Shakai Kaiso (Modernization and Social Stratification), Tokyo: University of Tokyo Press, p.35. Paradoxically, though, Japanese sociologists have come to pay more serious attention to social inequality and increasing "gap" between poor and rich without mentioning class issues.

${ }^{3}$ Yang, Jonhoe, 2005, "Kankoku no Chusan Kaikyu (Middle Classes in South Korea)", in Sonoda, S., ed., , Higashi Ajia no Kaiso Hikaku (Social Stratification in East Asia in Comparative Perspective), Tokyo: Chuo University Press, p. 158

${ }^{4}$ Hsiao, H.H.Michael, ed., 1999, East Asian Middle Classes in Comparative Perspective, Taipei: Institute of Ethnology, Academia Sinica.

${ }^{5}$ Lui, Tai-lok and Wang Zhijing, 2003, Xianggang Zhongchan Jieji Chujing Guancha (Observation of Middle Class's Crisis in Hong Kong), Hong Kong: Joint Publishing (Chinese); Tan, Ern Ser, 2004, Does Class Matter? : Social Stratification and Orientations in Singapore, Singapore: World Scientific Publishing.

${ }^{6}$ Xu, Xinxin, 2000, Dangdai Zhongguo Sheshui Jiegou Bianqian yu Liudong (Social Change and Social Mobility in Contemporary China), Beijing: Shehui Kexue Wenxuan Chubanshe Lu, Xueyi, ed., 2002, Dangdai Zhongguo Shehui Jieceng Yanjiu Baogao (Research Report on Social Stratification in Contemporary China), Beijing: Shehui Kexue Wenxuan Chubanshe; Zhou, Xiaohong, 2005, Zhongguo Zhongchang Jieceng Diaocha (Survey of the Chinese Middle Classes), Beijing: Shehui Kexue Wenxuan Chubanshe.

${ }^{7}$ Shigeto Sonoda, 2008, Fubyodo Kokkoa Chugoku (Social Inequality in China), Tokyo: Chuo Koron.

${ }^{8}$ Hsiao, H. H. Michael, ed., 1999, East Asian Middle Classes in Comparative Perspective, Taipei: Institute of Ethnology, Academia Sinica. Hsiao, H.H. Michael, ed., 2001, Exploration of the Middle Classes in Southeast Asia, Taipei: Program for Southeast Asian Area Studies, Academia Sinica.

${ }^{9}$ Hattori, Tamio, et.al, eds., 2002, Ajia Chukanso no Seisei to Tokushitsu (The Emergence and Features of the Asian Middle Classes), Tokyo: the Institute of Developing Economies .

${ }^{10}$ Sonoda, Shigeto, ed., 2005, "Shokugyo Hyoka no Shakai Rikigaku: Nicchu Hikaku karano Shiten (Social Dy-

2 | Journal of Contemporary Eastern Asia, Volume 8, No.2
} 
mon framework or standardized dataset was used in these projects.

Such lack of extensive East Asia-wide research is primarily due to lack of good data archives on social stratification in this region. In other words, East Asia is a place where "data accumulation and service have long remained until recently," $"$ which makes it difficult to formulate hypotheses on East Asian middle classes by using standardized empirical data. In spite of this, some social scientists have come to look at urban middle classes in East Asia as a homogeneous entity without empirical background. For example, Tamotsu Aoki, an anthropologist who pointed out the emergence of homogeneous urban middle class in the mid 1990s, tells us that such a homogeneous social class will be a foundation for future community building in East Asia.

"It is evident that 'urban middle class' is emerging in countries or regions which attained economic development Those who belong to this class share same characteristics as having good educational background, common life-style, knowledge and hobbies. They are free from narrow-sighed nationalism, religious fundamentalism, or ethno-centrism. They are basically international in nature and respect their private and family life [...]. This social class prepared social foundation of 'cultural exchange' among East Asian countries, and they are now creating their own 'common identity'. Political leader's statements cannot create such 'common identity' but I believe that increasing linkage among urban middle class in Asian societies is promoting 'cultural exchange' and 'mutual understanding' which would be a foundation for future 'community' or 'union' among East Asian countries."12

Therefore, what kinds of socio-economic traits can be observed among new middle class populations in East Asia? Do they really share any similar characteristics? In the former part of this paper, the author explores some hypotheses on new middle class populations in contrast with working class populations to draw a rough picture of their characteristics by using the data of AsiaBarometer survey in 2006. ${ }^{13}$

\section{Data}

AsiaBarometer was initiated and promoted by Inoguchi, a political scientist in Japan. This large scale survey began in 2003, and the survey has been conducted annually, covering different countries from year to year. ${ }^{14}$ Because AsiaBarometer was originally designed to measure mainly political orientations and attitudes in Asian countries from Japan to Afghanistan, such

\footnotetext{
namics of Occupational Evaluation: An Insight from China-Japan Comparison)" in Sonoda, S. ed., op.cit .

${ }^{11}$ Inoguchi, Takashi et. al. eds., 2006, Human Beliefs and Values in Striding Asia, Tokyo: Akashi Shoten, p.19.

12 Aoki, Tamotsu, 2005, "Higashi Ajia Kyodotai eno Michi (Road to East Asian Community)," Mainichi Newspaper dated $5^{\text {th }}$ of June.

${ }^{13}$ It is a well-known fact that middle classes are composed of new middle class and old middle class and they show some different traits. It is desirable, therefore, to distinguish them so that our observation will be more meaningful. Because sample size of old middle class is small, however, we could not help excluding it from our analysis.

14 Raw data of 2003 ,2004, and 2005 AsiaBarometer survey: https://www.asiabarometer.org/
} 
sociologically important items as respondents' occupational prestige or class identification and respondents' parents' educational backgrounds and occupations are excluded from the questionnaire. It is, therefore, impossible to measure inter-generational mobility by using AsiaBarometer 2006 data, but some items included in the questionnaire might illustrate urban middle classes' socio-cultural backgrounds and socio-political orientations.

Table 1: Overview of Data Collection

\begin{tabular}{|c|c|c|}
\hline Country & Sample Size & Sampling Areas and Collected Samples \\
\hline China & 2,000 & Eastern (840), Central (760), Western (400) \\
\hline Hong Kong & 1,000 & Hong Kong Island (203), Kowloon Peninsula(311), New Territories (486) \\
\hline Japan & 1,003 & $\begin{array}{l}\text { Hokkaido/Tohoku (120), Kanto (330), Chubu (182), Kinki(170), Chu- } \\
\text { goku/Shikoku (91), Kyushu (110) }\end{array}$ \\
\hline South Korea & 1,023 & $\begin{array}{l}\text { Seoul Metropolitan Area (507), Middle Area (134), Southwest Area (111), South- } \\
\text { east Area (271) }\end{array}$ \\
\hline Singapore & 1,038 & Northern (352), Eastern (27), Southern (334), Western (294), Central (32) \\
\hline Taiwan & 1,009 & Northern (476), Western (240), Southern (290) \\
\hline Vietnam & 1,000 & Northern(250), Central(250), Southern (250), Mekong Delta(250) \\
\hline
\end{tabular}

AsiaBarometer 2006 contains roughly 1,000 samples from Japan, South Korea, Hong Kong, Taiwan, Vietnam, Singapore, and 2,000 samples from mainland China. A quota sampling method was adopted due to the difficulty of conducting random sampling in these areas, and all the data were collected from cities in different areas because of budget constraints. It might be desirable to use each country's data at the city level to talk about new middle class populations in East Asian metropolises, but we cannot help using national data due to the small size of the sample.

Table 2: Volume of New Middle Class and Working Class in East Asia

\begin{tabular}{lccc}
\hline & New Middle Class & Working Class & Total \\
\hline China & 458 & 366 & 824 \\
Hong Kong & 269 & 331 & 600 \\
Japan & 174 & 374 & 548 \\
South Korea & 151 & 188 & 339 \\
Singapore & 307 & 345 & 652 \\
Taiwan & 176 & 330 & 506 \\
Vietnam & 150 & 449 & 599 \\
\hline Total & 1,685 & 2,383 & 4,068 \\
\hline
\end{tabular}

In this paper, we categorized those who are senior managers (company director, no lower in rank than a manager of a company section in a company with 300 or more employees, or a manager of a department in a company with less than 300 employees), employed professionals or specialists (hospital doctors, employed lawyers, engineers, etc.), clerical workers as "new middle class" and those who are manual workers (including skilled and semi-skilled), drivers, 
sales workers, or other workers as "working class"15 and try to make their comparison. Table 2 shows the volume of new middle class and working class in our samples.

\section{Hypotheses}

What are the distinctive features of new middle class populations in comparison with working class populations in East Asia? In order to grasp their general traits, we prepared ten hypotheses tentatively, five of which deal with socio-cultural background and the rest of which are concerned with socio-political orientations.

\section{Socio-cultural Background}

According to Hsiao, ${ }^{16}$ a large part of the new middle class in Seoul, Taipei, Hong Kong and Singapore are first generation middle class whose parents were industrial workers or farmers before the 1970s. It is certain that such newly developing countries like China have more and more young employees who are working in modern offices or subsidiaries of multinational companies. If this is the case, we can expect that

Hypothesis 1a: Those who belong to the new middle class are younger than those who belong to the working class.

With the expansion of the commercial and service sector, large proportion of female workers find their jobs in these sectors. According to Seiyama, ${ }^{17}$ a "growing number of professional occupations especially in educational or medical sectors allowed married female workers to continue their career because of their 'femininity,' while increasing number of clerical works created job opportunities for women" in Japan, but if this trend can be applied to industrialization in all over East Asia, we can say that

Hypothesis $1 b$ : The new middle class has a larger proportion of females than the working class.

As is often pointed out, the emergence of new middle class goes hand in hand with the spread of higher education. With the spread of meritocracy, people from lower classes also come to take part in competitive university entrance examinations to attain much better social status as "white collar" workers. ${ }^{18}$ If so,

Hypothesis 1c: The new middle class has more university graduates than the working class.

\footnotetext{
15 Konno, Hiroaki, 2006, "Toshi Chukanso no Doko (Orientations of Urban Middle Classes)" in Niitsu, K. and Yoshihara N., eds., Gurobaru-ka to Ajia Shakai (Globalization and Asian Societies), Toshin-do, p.189.

16 Hsiao, 1999, ibid. ,p. 4.

17 Seiyama, 2000, ibid., p.22

18 Takeuchi, Yo, 1995, Nihon no Meritokurashi (Japan's Meritocracy), Tokyo: University of Tokyo Press, pp.86-88.
} 
Globalization as well as higher education is a key to understanding the characteristics of new middle class. As is often pointed out, the emergence of new middle class is the result of globalization which has produced a global scale of consumerism. If so,

Hypothesis 1d: The new middle class' daily lives are more exposed to globalization than those of the working class.

It is frequently reported that newly emerging middle class families respect education for their children and sometimes they send their children abroad with their mothers to study foreign languages, especially English. In case of South Korea, for example, men who stay in South Korea to send money to their children and wife abroad are call kirogi appa ('fathers of wild geese' in Korean). This practice has been described as a "social disease" of middle classes which puts too much emphasis on educational attainment through studying abroad. ${ }^{19}$ If so,

Hypothesis 1e: The new middle class has a more fluent English-speaking population than the working class.

\section{Socio-Political Orientations}

Needless to say, new middle class populations are the product of industrialization and modernization. It is natural to assume that people who belong to new middle class show those socio-political orientations which are related with "modernity." In fact, Zhang discusses that one of the social functions of new middle class is to establish modern values or norms in contemporary China. ${ }^{20}$

In AsiaBarometer, two questions have to do with a "traditional-modern" nexus. One is about nepotism, which shows "particularistic" value, and the other is about secularization of religious behavior.

Hypothesis 2a: The new middle class is more prone to support anti-nepotism than the working class.

Hypothesis $2 b$ : The new middle class is more secularized than the working class.

New middle class populations in East Asia used to be regarded as promising drivers of social movements through which they could develop more gender-equal, environmental-oriented, and democratic societies. ${ }^{21}$ Hsiao points out that the new middle class in Taipei is concerned with quality of life including environmental issues and social welfare issues, ${ }^{22}$ and major players of

\footnotetext{
${ }^{19}$ Cha, Jongchun, 2005, "Gendai Kankoku niokeru Shakai Ido (Social Mobility in Contemporary South Korea)" in Sonoda, S. ed., op.cit, p.59.

${ }^{20}$ Zhang, Wanli, 2005, "Taito suru Chukanso to Chugoku Shakai no Genzai (Emerging Middle Strata and Contemporary China)" in Sonoda, S. ed., op.cit., p.191.

${ }^{21}$ Rodin, Gary, ed., 1996, Political Opposition in Industrializing Asia, New York and London: Routlege.

${ }^{22}$ Hsiao, , 1999, ibid., , p.71.

6 | Journal of Contemporary Eastern Asia, Volume 8, No.2
} 
consumer movements, environmental protection movements, women's movements, and democratic movements are those who belong to the new middle class. If so, we can say that,

Hypothesis 2c: The new middle class is more supportive of gender-equality policy than the working class.

Hypothesis $2 d$ : The new middle class is more concerned about environmental issues than the working class.

Hypothesis $2 e$ : The new middle class has more pro-democratic attitude than the working class.

\section{Diversity among Societies}

How much we can deal with seven societies' data as one unit is a sensitive issue. Area study specialists are apt to put an emphasis on the "uniqueness" of the each society they are studying and some of their observations are worthy of consideration. Sonoda, for example, points out that income discrepancy and social status gaps between the new middle class and the working class is larger in China than in Japan, ${ }^{23}$ and many scholars point out the cultural diversity of middle class populations in East Asian countries. ${ }^{24}$ If so,

Hypothesis 3: The difference between the new middle class and the working class or characteristics of new middle class, per se, shows different patterns among societies.

\section{Results of Analysis}

\section{Test of Ten Hypotheses}

In order to verify ten hypotheses above, it is necessary to make operational definitions of some concepts.

As to the exposure to globalization, we prepared six items asking whether 1) respondent's family member or relative lives in another country, 2) respondent has traveled abroad at least three times in the past three years, 3) respondent has friends who are from other countries, 4) respondent watches foreign-produced programs on TV, 5) respondent has communication with people in other countries via the Internet or email, and 6) respondent has contact with organizations or people in other countries in job, and we recorded a 'globalization score' ranging from six points to zero point by adding the number of items that respondents answered yes to.

As to 'anti-nepotism', we prepared such questions as, "In the company's employment examinations, a relative of yours got the second highest grade, scoring only marginally less than

\footnotetext{
${ }^{23}$ Sonoda, Shigeto, 2006, "The Attainment of Nengli-zhui (Meritocracy): Changing Value System and Political-Economic Transformation in China," in Kojima, T. ed., Restrucuring China, Tokyo: Toyo Bunko.

${ }^{24}$ Hsiao, 1999, ibid., pp. 45-47; Hattori, 2002, ibid. ,p. 20.
} 
the candidate with the highest grade. In such a case, which person would you employ?"

Secularization, or religiosity, was measured using the question, "How often do you pray or meditate?" and the score was determined on a scale from 1 point (Never) to 5 points (Daily).

Support of gender-equality policy and environmental policy were measured by the answers to the question of how much government should spend in improvement of the social status of women or the environment, determined on a scale from 1 point (spend much less) to 5 points (spend much more).

Finally, pro-democratic attitude was scored by answers to the question of whether the respondent thinks a democratic political system is very good ( 3 points), fairly good ( 2 points), or bad (1 point) for his or her country.

Because age, exposure to globalization, religiosity, support of gender-equality policy and environmental policy, and pro-democratic attitude are numerical data, we used t-test to check whether new middle class populations and working class populations show statistically significant differences in terms of their average scores, and cross-tabulation analysis (chi-test) was used for other variables. The results of analysis are shown in Table 3.

Table 3: Results of Test of Ten Hypotheses

\begin{tabular}{|c|c|c|c|c|}
\hline & New middle class & Working Class & Sig. & Units (Variables) \\
\hline 1a & 36.4 & 39.5 & ++ & Years Old(Age) \\
\hline $1 \mathrm{~b}$ & 47.8 & 64.5 & ++ & $\%$ of Male (Sex) \\
\hline $1 \mathrm{c}$ & 59.4 & 16.3 & ++ & $\begin{array}{l}\% \text { of College/University Gradu- } \\
\text { ate(Academic Career) }\end{array}$ \\
\hline $1 d$ & 1.47 & 0.98 & ++ & $\begin{array}{l}6 \text { Point Scale (Exposure } \\
\text { to Globalization) }\end{array}$ \\
\hline $1 \mathrm{e}$ & 18.9 & 6.5 & ++ & $\begin{array}{l}\% \text { of Fluent Speaker of English } \\
\text { (Fluency of English) }\end{array}$ \\
\hline $2 \mathrm{a}$ & 68.2 & 65.6 & & $\begin{array}{l}\% \text { of "The person with the high- } \\
\text { est grade" (Anti-nepotism) }\end{array}$ \\
\hline $2 b$ & 2.06 & 2.14 & & 5 Point Scale (Religiosity) \\
\hline $2 \mathrm{c}$ & 3.49 & 3.40 & ++ & $\begin{array}{l}5 \text { Point Scale (Support of Gen- } \\
\text { der-equality Policy) }\end{array}$ \\
\hline $2 d$ & 3.82 & & ++ & $\begin{array}{l}5 \text { Point Scale (Support of En- } \\
\text { vironmental Policy) }\end{array}$ \\
\hline $2 \mathrm{e}$ & 2.32 & $\begin{array}{l}3.67 \\
2.25\end{array}$ & ++ & $\begin{array}{l}3 \text { Point Scale } \\
\text { (Pro-Democracy) }\end{array}$ \\
\hline
\end{tabular}

++ Significant at .01 level

It is evident that variables on socio-cultural background are more effective in dividing new middle class and working class populations than socio-political variables in East Asia. In other words, it is possible to characterize the new middle class by age, sex, academic career, exposure to globalization, or English-speaking population easily, but it's difficult to distinguish East Asian new middle class populations from working class populations by their socio-political orientations, especially their anti-nepotism attitude or religiosity. 


\section{Hypothesis-testing of Diversity among Societies}

Then, how much diversity in the gap between the new middle class and the working class can be seen in East Asian societies? Table 4 shows the result of t-test and cross-tabulation analysis about ten hypotheses mentioned above in each society.

Table 4: Diversity among Societies

\begin{tabular}{|c|c|c|c|c|c|c|c|c|}
\hline & China & HK & Japan & $\begin{array}{l}\text { South } \\
\text { Korea }\end{array}$ & Singapore & Taiwan & Vietnam & $\begin{array}{c}\text { Among } \\
\text { Societies }\end{array}$ \\
\hline $1 a$ & + & ++ & /I & ++ & ++ & ++ & ++ & ++ \\
\hline $1 b$ & ++ & ++ & + & /I & ++ & ++ & /I & ++ \\
\hline $1 \mathrm{c}$ & ++ & ++ & ++ & ++ & ++ & ++ & ++ & ++ \\
\hline $1 d$ & ++ & ++ & + & ++ & ++ & ++ & ++ & ++ \\
\hline $1 e$ & ++ & ++ & ++ & ++ & ++ & ++ & ++ & ++ \\
\hline $2 a$ & /I & + & /I & /I & /I & /I & /I & ++ \\
\hline $2 \mathrm{~b}$ & /I & $\cdots$ & /I & /I & /I & /I & ++ & ++ \\
\hline $2 c$ & + & + & + & /I & /I & + & /I & ++ \\
\hline $2 d$ & + & II & /I & + & /I & /I & + & ++ \\
\hline $2 e$ & + & $/ /$ & /I & $/ /$ & /I & $/ /$ & $\mathbf{N}$ & $\mathbf{N}$ \\
\hline Dat & $\begin{array}{l}01 \text { Level } \\
\text { ilable }\end{array}$ & + Verif & t.05 Level & //Not & nificant & Counte & at .05 Level & \\
\hline
\end{tabular}

Interestingly, academic career, exposure to globalization, and English fluency are three statistically significant factors which distinguish between new middle class and working class populations in every society. On the other hand, however, the remaining eight hypotheses were verified in some, but not all, countries, and the characteristics of the new middle class in each society differs from every other, which supports hypothesis 3 on diversity among societies.

Japan is the only country where the average age of the new middle class ( 42.3 years old) is similar to that of the working class (41.2 years old), probably because Japan has the longest history of having new middle class. In other societies, however, the new middle class is relatively younger than the working class probably due to the recent development of new middle class in these societies (see Figure 1).

As to sex composition, South Korea and Vietnam are the exceptions in the sense that they have an equal percentage of male employees in the new middle class and the working class. The reasons, however, seem to be different in South Korea and Vietnam. South Korea is still a 'male dominant society' where male employees dominate not only the working class but also the new middle class, while Vietnam has inherited the legacy of equal participation in the workplace by both sexes advocated under socialist rule (see Figure 2). 
Figure 1: Age of New Middle Class and Working Class (Unit: Years Old)

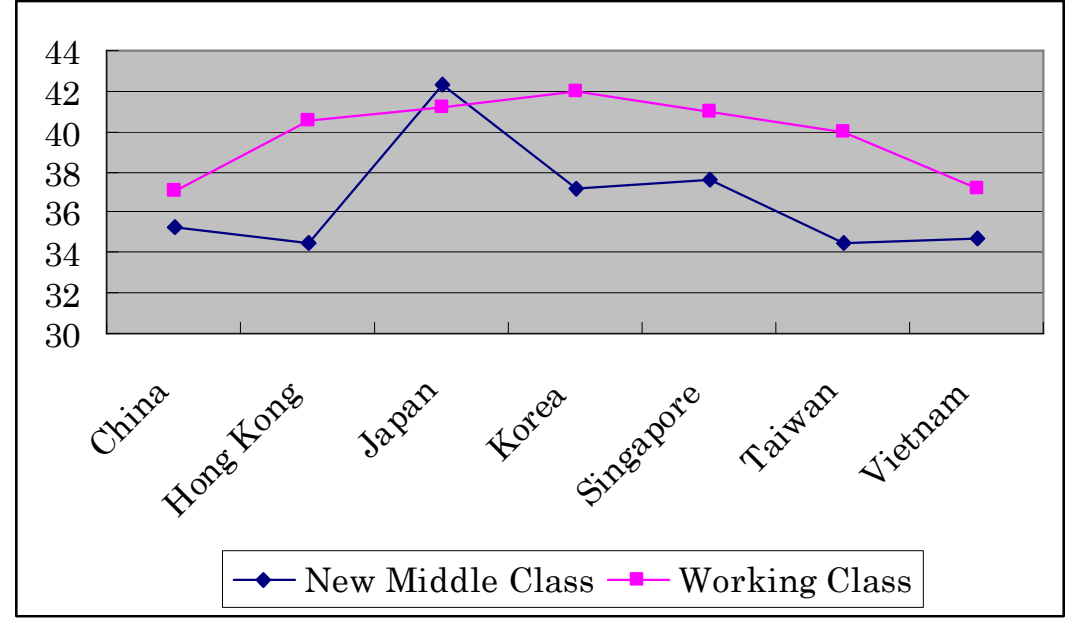

Figure 2: Sex Composition of New Middle Class and Working Class (Unit: \%)

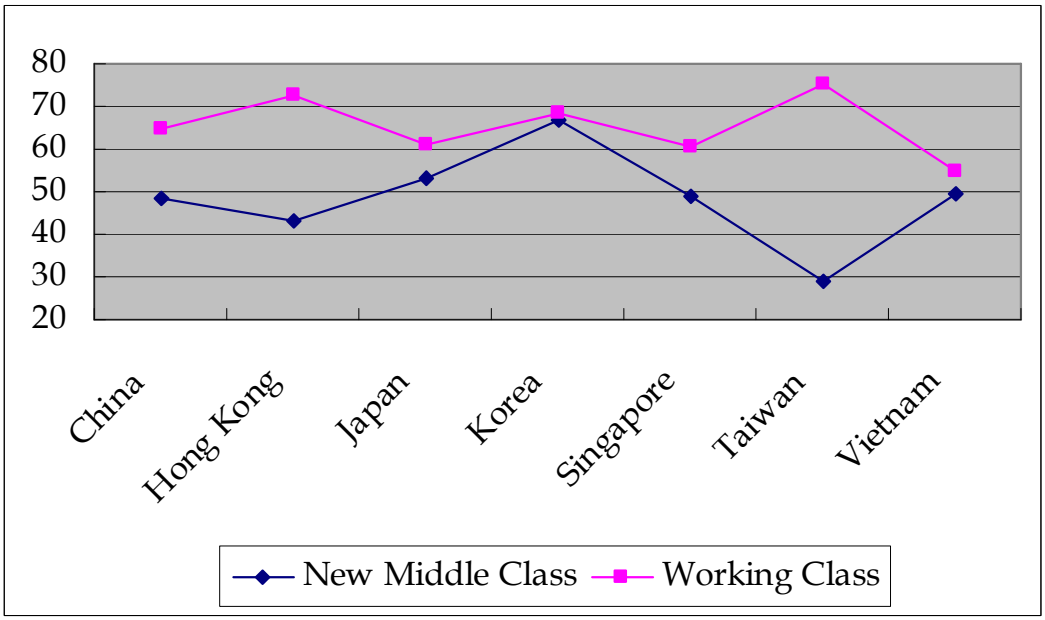

Figure shows percentage of female among class categories.

\section{Two Clusters of New Middle Class}

A large diversity among countries makes it worthwhile to categorize East Asian new middle class into several types. What types of new middle class are there in East Asia? In the latter part of this paper, the author tries to identify some types of new middle class in East Asia. Figure 3 shows the composition of two clusters of new middle class which were obtained by two-step cluster analysis by using the ten variables used in this paper; one can be called the 'English-speaking type' (Singaporean and some part of Hong Kongese; $n=307$ ) and the other can be called the "non-English speaking type" or just "Confucian type" (Japanese, South Korean, Chinese, Taiwanese, and some part of Hong Kongese; $n=1117)^{25}$ because of the following reasons. ${ }^{26}$

\footnotetext{
${ }^{25}$ Because we were not allowed to ask informants' ideas on politics in Vietnam, Vietnamese samples are excluded from cluster analysis.

${ }_{26}$ This finding is basically similar to the one that the author got through the analysis of ASEAN+3 data in 2004 . See Sonoda, Shigeto, 2006, "New middle class in East Asia: Their Socio-cultural Background and Socio-political 10 | Journal of Contemporary Eastern Asia, Volume 8, No.2
} 


\section{Figure 3: Composition of Two Clusters of Middle Classes in East Asia}

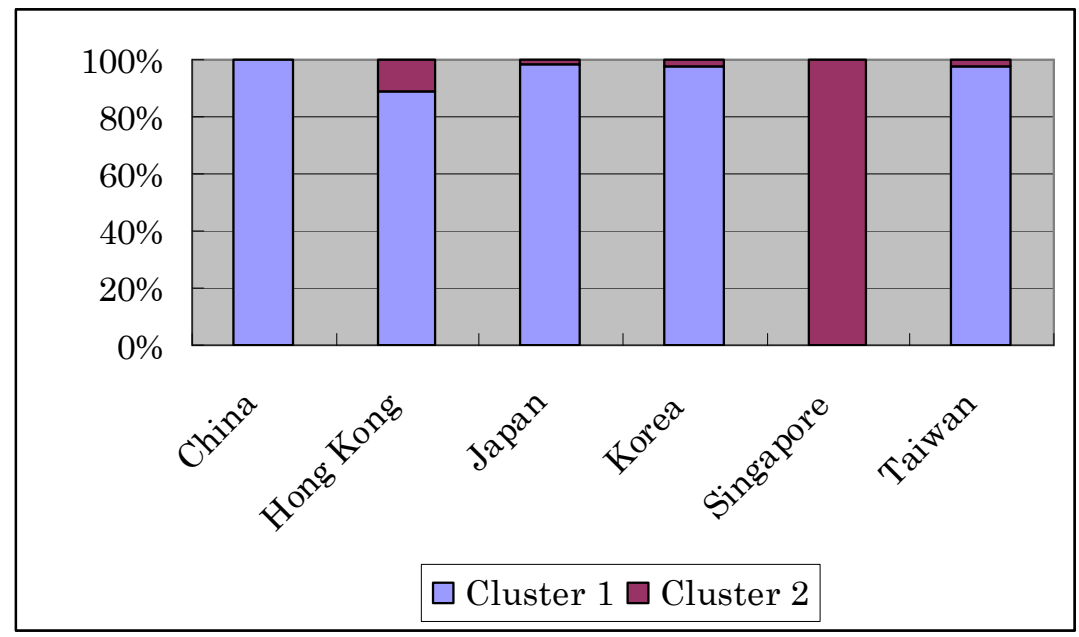

Figure 4: Fluency of English in Two Clusters

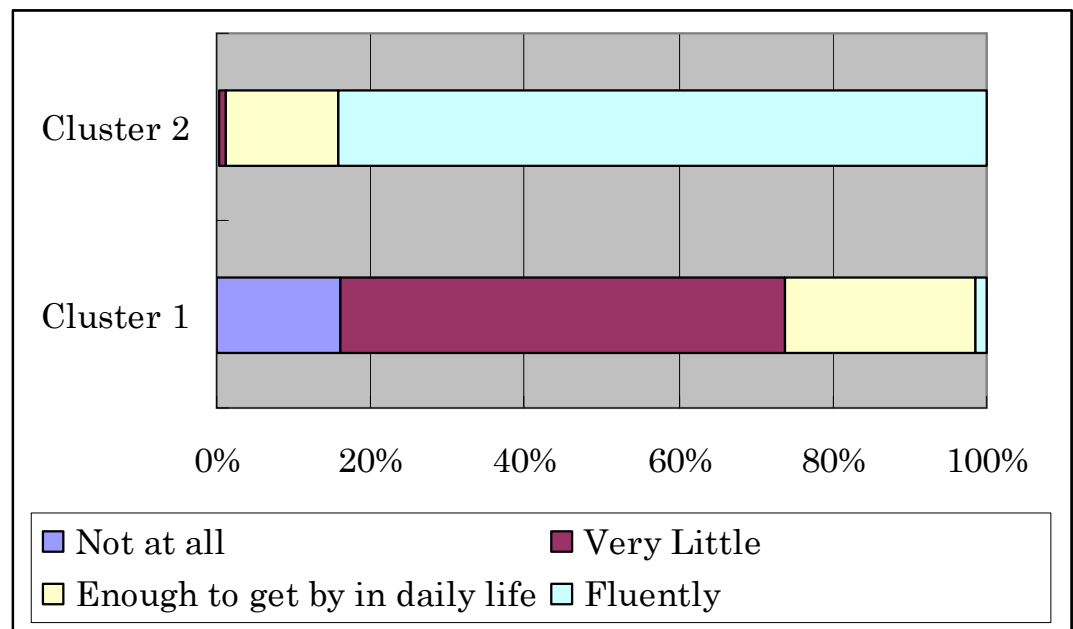

Firstly, Cluster 1 is outstandingly fluent in English and more exposed to globalization than Cluster 2 (see Figure 4 and Figure 5). It is easily understood that fluency in English makes it possible for Cluster 1 to enjoy a globalized life, but it doesn't mean that they are free from religious beliefs. On the contrary, the new middle class of Cluster 2 is more educated and secularized than that of Cluster 1 (see Figure 5 and Figure 6), which is another reason why Cluster 2 can be called "Confucian type." 27 In fact, within Cluster 2, those who answered they believed in no particular religion is as many as 69.0 percent while only 20.9 percent of Cluster 1 an-

Orientations in Comparative Perspective", in Inoguchi T. ed., AsiaBarometer Project Series 3: International Realignments and Internal Stratifications as Gauged through the AsiaBarometer Survey, pp. 24-39.

${ }^{27}$ Confucianism is sometimes called "education-oriented" and "secularized" ethics, but Kaji maintains that essence of Confucianism is not in rituality but in religiosity in the sense that those who live in Confucian cultures still worship ancestors and have strong filial piety. Our analysis reveals, however, that new middle class in Confucian cultures pray or mediate in their daily life only on special occasions, which doesn't support Kaji's observations. See Kaji, Nobuyuki, 1990, Jukyo towa Nanika (What is Confucianism?), Tokyo: Chuo-Koron, p.226. 
swered that they believe in no particular religion. ${ }^{28}$

Figure 5: Socio-cultural Background and Socio-political Orientations in Two Clusters (Unit: Points)

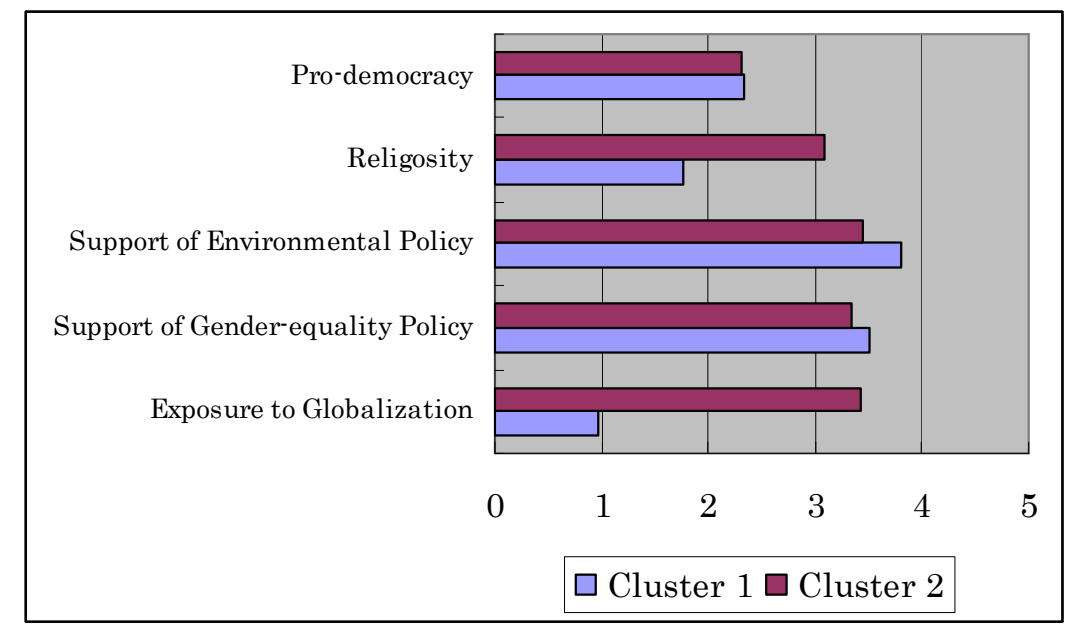

Figure 6: Academic Career of Two Clusters

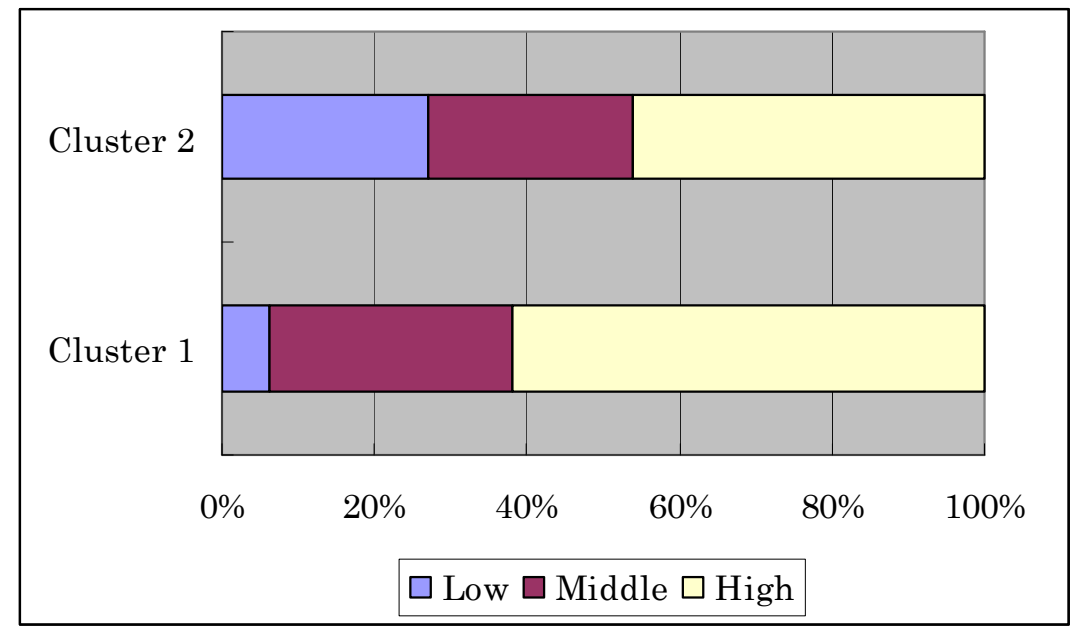

"Low" is junior high graduate level, "Middle" is high school graduate level, and "High" is college/university graduate level.

Last but not least, a difference between Cluster 1 and Cluster 2 is that the former is more amenable to nepotism (see Figure 7). In other words, those who answered 'my relative' when asked whether they would employ a person with highest grade or their relative can be seen more in Cluster 1 than in Cluster 2. This is the last reason why Cluster 1 can be named the 'Confucian type which puts more emphasis on such particularistic ties such as blood relationship. ${ }^{29}$

\footnotetext{
${ }^{28}$ Paradoxically, no respondent among cluster 1 answered that they believe in Confucianism. Needless to say, "Confucian-type" is an ideal-type which doesn't coincide with the respondent's religious belief.

${ }^{29}$ There are many books and papers which point out Confucian society's preference for blood relation ties. As to comparative study of Japan and China from this angle, see Sonoda, Shigeto, 2001, Chugokujin no Shinri to Kodo (Psychology and Behavior of Chinese People), Tokyo: NHK Books .
} 
Figure 7: Anti-Nepotism Attitudes of Two Clusters

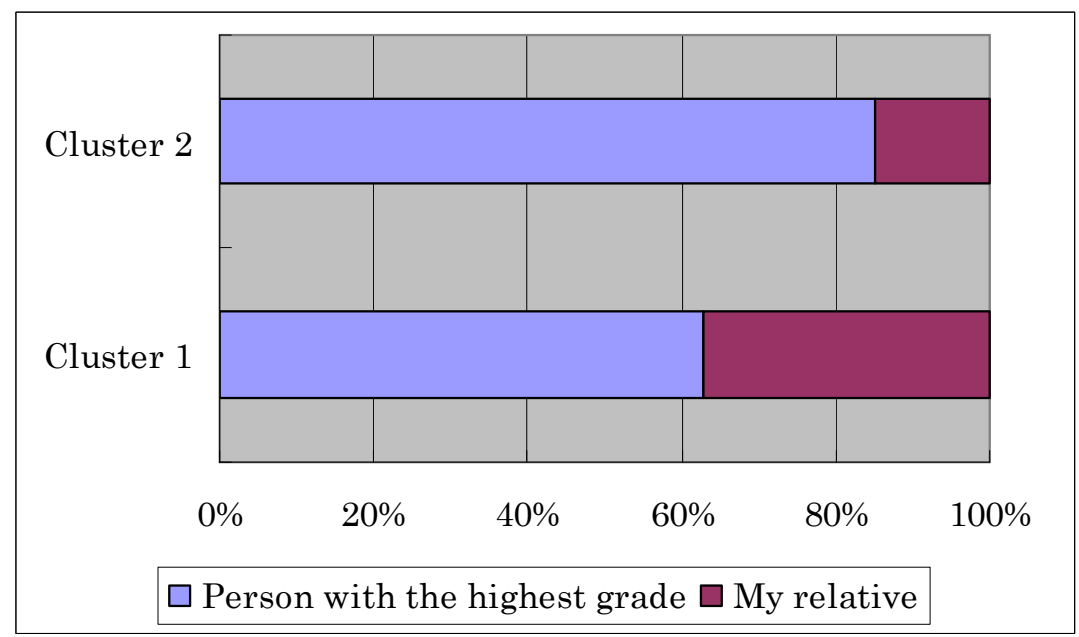

\section{Summary and Discussion}

The data of the AsiaBarometer survey in 2006 collected in East Asia revealed the following findings.

The new middle class in East Asia is much better educated, more exposed to globalization, and more fluent speaker of English than the working class in every country. They are younger except in Japan and have more female employees except in South Korea and Vietnam than working class. All in all, the new middle class shows similar socio-cultural backgrounds.

As to Socio-political orientation, however, the new middle class does not show any clear and distinctive characteristics in every society. They are more supportive of gender-equality policy and environmental protection and more pro-democratic than the working class, but we cannot see any clear distinction between them in some societies like Singapore.

As the result of our cluster analysis, we found two different types of new middle class in East Asia: one is the 'English-speaking type' and the other is the 'Confucian type.' The latter is huge in volume, and they are highly educated but less exposed to globalization probably due to their lacking English fluency. They are more secularized and particularistic than the 'English-speaking type' in nature. ${ }^{30}$

It is evident that the new middle class in Singapore shows different traits than its counterparts in other East Asian societies in the sense that their lives are very globalized on the one hand, and their socio-political orientations do not show any of the distinctiveness which has been identified with new middle class in advanced societies on the other.

Interestingly, only about 10 percent of the new middle class in Hong Kong, which has a long

\footnotetext{
${ }^{30}$ The author found interesting relationship between the types of new middle class and their identity as Asians. To be concretely, among English-speaking new middle class, those who use the Internet more frequently have stronger identity as Asians, but among non-English new middle class, we could observe opposite trait. It is thus meaningful to distinguish two different types of new middle class in discussing their characteristics in Asia. See Sonoda, Shigeto, 2007, "Emergence of New middle class and the Formation of New Asian Identities?," Nishikawa, J. and K. Hirano eds., Kokusai Ido to Shakai Henyo (International Mobility and Social Change), Tokyo: Iwanami Shoten Publishers.
} 
tradition of English education under British colonial rule in common with Singapore, , belong to the 'English-speaking type,' which might have something to do with the handover of Hong Kong to China. In order to verify this, however, we need to trace historical change over time.

Needless to say, socio-cultural background and socio-political orientations of the new middle class in East Asia have been formed in their distinct historical contexts. These may include, the length of time after the birth that a new middle class emerged, the influence of socialist regimes, a tradition of English-learning education, the cultural legacy of Confucianism, a colonial tradition, and so on. These factors have been contributing to form unique characteristics of the new middle class in East Asia.

Some readers might suspect that the two types of new middle class in East Asia may converge due to the widespread of English language as an international language, but it is not the case. In other words, respondents' ages have no correlation with the type of new middle class they belong to, which makes it difficult for two types of new middle class to converge. Elite universities in Tokyo, Seoul, Beijing, Shanghai, Taipei, and Hanoi, most of which are national universities, have been promoting English education, but it is doubtful whether such efforts will bring about the convergence of the new middle class in East Asia.

It is clear that economic globalization has produced new middle class, but the historical background which fostered it still has a strong influence on its socio-political characteristics. Some life-styles choices, like drinking Coca-Cola, eating McDonald's hamburgers, living in Western-type condominium, using Western-invented personal computers, and wearing Western-style suits, are easily accepted in daily life, but it may take a long time especially for the 'Confucian type' of middle class in East Asia to change their locally-embedded socio-political creeds or behaviors.

Finally, can we find any 'Muslim' type of new middle class in Kuala Lumpur or Jakarta or 'Buddhist' type of new middle class in Bangkok? Does the City of Delhi or Mumbai have a 'Hindu' type of new middle class? If so, what characteristics do they have?

These questions will be addressed by the author's forthcoming papers which will use AsiaBarometer 2007 and 2008 data. 